\title{
Characteristics, Etiologies and Trends of Hepatocellular Carcinoma in Patients without Cirrhosis: A United States Multicenter Study
}

\author{
Samer Gawrieh ${ }^{1}$, Lara Dakhoul ${ }^{1}$, Ethan Miller ${ }^{2}$, Andrew Scanga $^{3}$, Andrew deLemos $^{4}$, Carla \\ Kettler ${ }^{1}$, Heather Burney ${ }^{1}$, Hao Liu ${ }^{1}$, Hamzah Abu-Sbeih, MD²; *Naga Chalasani ${ }^{1},{ }^{*} J u l i a$ \\ Wattacheril ${ }^{5}$
}

Affiliations: 'Indiana University School of Medicine, Indianapolis, IN; ${ }^{2}$ MD Anderson Cancer

Center, Houston, Texas, MD, ${ }^{3}$ Vanderbilt University School of Medicine, Nashville, Tennessee;

${ }^{4}$ Atrium Health, Charlotte, NC, ${ }^{5}$ Columbia University Vagelos College of Physicians and

Surgeons, New York, NY

${ }^{*} \mathrm{NC}$ and JW are co-senior authors.

Short title: NAFLD and non-cirrhotic HCC

Key Words: Nonalcoholic fatty liver disease; Hepatitis C; Hepatitis B; Hepatocellular Carcinoma

Word Count: 6113 (Main text and references)

Tables: 6

Figures: 3

\section{Corresponding Authors}

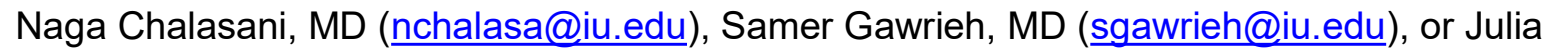
Wattacheril, MD (jiw2151@cumc.columbia.edu)

This is the author's manuscript of the article published in final edited form as:

Gawrieh, S., Dakhoul, L., Miller, E., Scanga, A., deLemos, A., Kettler, C., Burney, H., Liu, H., Abu - Sbeih, H., Chalasani, N., \& Wattacheril, J. (2019). Characteristics, aetiologies and trends of hepatocellular carcinoma in patients without cirrhosis: A United States multicentre study. Alimentary Pharmacology \& Therapeutics, 50(7), 809-821. https://doi.org/10.1111/apt.15464 
Disclosures: Dr. Dakhoul, Dr. Scanga, Dr. Liu, Dr. Abu-Sbeih, MD, Carla Kettler, BS, Heather Burney, MS declare no conflicts of interest. Dr. Gawrieh consulting: TransMedics, research grant support: Cirius, Galmed and Zydus. Dr. Chalasani had paid consulting activities with following companies in last 12 months: Abbvie, Shire, NuSirt, Afimmune, Axovant, Allergan, Madrigal, Coherus, Siemens, and Genentech. He has received research support from Lilly, Galectin, Gilead, Exact Sciences, and Cumberland. Dr. Miller serves on the physician advisory board of Bristol-Myers Squibb. He is a minority holder of stock in Amgen. Dr. deLemos had paid consulting activities with Gilead, Vital Therapies, and Achaogen in the last 12 months. Dr. Wattacheril has paid consulting activities with Astra Zeneca and has received research support from Janssen, Genfit, and Intercept, Galectin, Gilead, Zydus, Conatus, Shire.

Author's contributions: All authors contributed to study concept, data analysis, manuscript preparation.

Acknowledgements: The following individuals have contributed to the data extraction: Keaton R. Jones, MD and Chelsey McShane, MD (Indiana University School of Medicine), Essam Khalifa, MD, (MD Anderson Cancer Center), Emily Mao, MD (Baylor College of Medicine), Barbara Channell, BSN, RN (Vanderbilt University School of Medicine), Krista Bossi, MS, Sarah LeStrange, MS, Patrick Roche, BS, Milin Patel, MD (Atrium Health), Averill Guo, MD, Sydney Pomenti, MD, Meaghan Phipps, MD, Jonathan Yeh, MSPA, MBA, PA-C (Columbia University Irving Medical Center), Alexandra Livanos, MD, PhD (Icahn School of Medicine at Mount Sinai). The Authors would like to thank Ms. Julianne Nanzer for her administrative assistance with our manuscript.

Source of funding: Supported in part by David W. Crabb Professorship Endowment at Indiana University School of Medicine (N.C.) 


\section{ABSTRACT}

Background: Limited data exists on the burden and features of non-cirrhotic hepatocellular carcinoma (HCC) in the United States.

Aims: To evaluate characteristics, etiologies, trends, and outcomes of non-cirrhotic HCC from 2000 to 2014 at 5 large US centers. Methods: Patient, tumor and liver disease etiology data were manually collected. The presence of underlying cirrhosis was assessed based on published criteria.

Results: Of 5,144 eligible patients with $\mathrm{HCC}, 11.7 \%$ had no underlying cirrhosis. Non-cirrhotic patients were older (64.1 vs 61.2 years), more frequently females (33.9\% vs $20.8 \%$ ), and less frequently Black (8.3\% vs. $12.4 \%$ ) ( $p<0.001$ for all). Among non-cirrhotic patients, non-alcoholic fatty liver disease (NAFLD) was the most common liver disease $(26.3 \%)$, followed by hepatitis C (HCV) $(12.1 \%)$, and hepatitis B (10\%). As of 2014, there was increased percentage of cirrhotic HCC and a decline in non-cirrhotic HCC mainly due to significant annual increases in cirrhotic HCC due to HCV [0.96\% $(p<0.0001)]$ and NAFLD [0.66\% $(p=0.003)]$. Patients with non-cirrhotic HCC had larger tumors (8.9 vs $5.3 \mathrm{~cm}$ ), were less frequently within Milan criteria (15\% vs $39 \%)$, more frequently underwent resection $(43.6 \%$ vs $8 \%)(p<0.001$ for all), and had better overall survival than cirrhotic HCC patients (median 1.8 vs 1.3 years, $p=0.004$ ).

Conclusions: Nearly $12 \%$ of HCCs occurred in patients without underlying cirrhosis, and NAFLD was the most common liver disease in these patients. During the study period, the frequency of non-cirrhotic HCC decreased whereas that of cirrhotic HCC increased. Although non-cirrhotic patients presented with more advanced HCC, their survival was better.

(Word Count: 250)

\section{INTRODUCTION}


Hepatocellular carcinoma (HCC) is the third leading cause of cancer-related deaths worldwide, causing more than 700,000 deaths per year ${ }^{1}$. HCC incidence rates have significantly increased in the United States (US), surpassed only by thyroid cancer ${ }^{2-5}$. Further, HCC mortality rate is the highest of all cancers in the US ${ }^{4}$.

While viral hepatitis and alcohol have traditionally been the main liver diseases driving the occurrence of $\mathrm{HCC}^{6,7}$, the new millennium has witnessed the emergence of non-alcoholic fatty liver disease (NAFLD) as a major contributor to the burden of HCC, not only in the US and Western countries but also at the global level ${ }^{8-11}$. Over the past 2 decades, NAFLD cirrhosis has been increasingly recognized as an important cause of $\mathrm{HCC}^{12-18}$. Recent studies based on national data have shown a significant and recent increase in NAFLD contribution to the HCC burden and mortality in the US $8,10,19,20$. In a study of United Network for Organ Sharing (UNOS) registry from 2002-2012, liver transplantation for HCC related to NAFLD has increased 4-folds compared to a two-fold increase for $\mathrm{HCC}$ related to hepatitis $\mathrm{C}$ virus (HCV), making NAFLD the most rapidly growing indication for liver transplantation for HCC in the US ${ }^{19}$. Between 20012013, HCV followed by NAFLD were the major contributors to rising rates of cirrhosis and HCC among US Veterans ${ }^{10}$. In a study of the Surveillance, Epidemiology and End Results (SEER) registries with Medicare-linkage files for HCC between 2004-2009, a 9\% annual increase in NAFLD related HCC was observed, exceeded only by a $13 \%$ annual increase in HCV related HCC. However, whether NAFLD contribution to the expanding HCC burden is exclusively via the cirrhosis-carcinogenesis pathway was not clear from these studies.

The development of HCC in a non-cirrhotic setting has long been recognized as an uncommon event in patients with chronic liver disease, occurring primarily in the setting of hepatitis B virus (HBV) infection ${ }^{21,22}$. Accumulating data from different case reports and studies over the past 2 decades have shown the same phenomenon occurs in the setting of non-cirrhotic NAFLD ${ }^{23-28 .}$ The mechanisms of carcinogenesis in the setting of non-cirrhotic NAFLD are not entirely clear, but the chronic inflammatory state associated with obesity and commonly seen with NAFLD, 
insulin resistance and lipotoxicity may alter hepatocyte proliferation and different modes of hepatocyte death, thus promoting a carcinogenic milieu ${ }^{29-32}$.

There seems to be geographical differences in the frequency of non-cirrhotic HCC in the setting of NAFLD; only $15 \%$ of patients with NAFLD and HCC were not cirrhotic in an Australian study $^{33}$, compared to $27 \%$ in a single center US study ${ }^{34}$, and up to $50 \%$ in European and Japanese studies ${ }^{35-38}$. However, beside population differences, some of these studies were based on data from single centers, had small study size, lacked specific criteria to define the non-cirrhotic status, or included only patients referred for surgical resection. The proportion of non-cirrhotic HCC in the US has not been adequately quantified.

While the trends of HCC related to specific underlying liver diseases in select populations in the US have been recently described based on the UNOS, Veterans Administration (VA), and SEER databases, these studies relied on International Classification of Diseases (ICD) codes for identifying underlying liver diseases or presence of obesity or diabetes to infer the presence of NAFLD $8,10,19$. No other large-scale data with direct ascertainment of the underlying etiology of liver disease and cirrhotic status is yet available in the US to allow for high-resolution evaluation of all comers with HCC. With the limitations in current literature ${ }^{39}$, it is unclear whether the rising incidence of NAFLD in the US has resulted in higher number of non-cirrhotic HCC. If this were true, it would have a major public health impact as the proportion of HCC linked to NAFLD is anticipated to be on the rise with the global and growing epidemic of obesity and metabolic syndrome.

To address these questions, we studied 5,144 patients with HCC seen at 5 major liver centers across the United States (US) over a 14.5 year period between 2000-2014. The primary objectives of this study were to 1) characterize the frequency and characteristics of non-cirrhotic $\mathrm{HCC}, 2)$ assess the trends of percentage of non-cirrhotic HCC over the study period, and 3) determine the contribution of NAFLD to the burden of non-cirrhotic HCC. As secondary 
objectives, we report on the treatment modalities these patients received and their survival compared to cirrhotic patients with HCC.

\section{METHODS}

\section{HCC case identification and characterization}

Using the institutional Cancer Registry at each participating site, all adult patients 18 years of age or older with HCC seen at the study centers ( Indiana University School of Medicine, Indianapolis, IN; MD Anderson Cancer Center, Houston, Texas, MD, Vanderbilt University School of Medicine, Nashville, Tennessee; Atrium Health, Charlotte, NC, Columbia University Vagelos College of Physicians and Surgeons, New York, NY) and their affiliate hospitals from January 2000 to June 2014 were identified. We performed manual chart review of each identified case to verify the diagnosis and extract the data. The data were managed centrally by the data coordinating center at Indiana University. The study was reviewed and approved by each participating site's Institutional Review Board.

The diagnosis of HCC required histological and/or radiographic evidence consistent with the American Association for Study of Liver Disease (AASLD) guidelines ${ }^{40,41}$. Histology was most often confirmed at the time of resection, transplantation, or death and not as the primary diagnostic modality for HCC across centers. Patients were excluded from this study if they had 1) uncertain HCC diagnosis; 2) fibrolamellar HCC; 3) cholangiocarcinoma; 4) tumor recurrence as the reason for referral to our institution; and 5) insufficient data in the medical records.

Demographics, comorbidities, clinical data and laboratory values and tumor characteristics were collected at the time of HCC diagnosis. For the tumor size, the largest tumor diameter was recorded for each patient. The presence of macrovascular invasion or distant metastases, TNM staging and whether the HCC was within Milan criteria were captured ${ }^{42,43}$. Although the Milan criteria were originally developed in patients with cirrhosis, these criteria are now universally known and provide easy summary of tumor burden in terms of size and number of lesions, 
therefore were used to define the HCC burden in non-cirrhotic patients in this study. All treatment modalities received throughout the disease course were manually extracted from medical records.

\section{Determination of comorbidities and underlying liver disease}

Physicians' documentation and/or presence of confirmatory laboratory tests were used to assess for the presence of the following medical co-morbidities: diabetes mellitus, hypertension, dyslipidemia, coronary artery disease, and peripheral vascular disease, as well as the following underlying liver disease etiologies: HCV, HBV, alcohol, autoimmune hepatitis, primary biliary cholangitis, primary sclerosing cholangitis, hemochromatosis, and alpha-1-antitrypsin deficiency. Alcohol abuse was defined as history of more than 3 drinks a day, clinical documentation of alcoholism/alcohol abuse, enrollment in a substance abuse treatment program, or history of alcoholic hepatitis ${ }^{44}$. NAFLD diagnosis required either a diagnosis assigned by the managing hepatologist and/or evidence of hepatic steatosis, either by imaging or by histology in the absence of an alternative liver disease ${ }^{45}$. The rare liver disease category included diseases like amyloidosis, sarcoidosis, cardiac cirrhosis, drug-induced chronic liver disease, and environmental exposure. Patients were classified as having unclear or unknown etiology of liver disease if, after extensive chart review, there was sufficient information to make a diagnosis of underlying etiology of disease, but no clear underlying etiology was found or if there was not sufficient data to make a diagnosis.

\section{Definition of the cirrhotic and non-cirrhotic status}

Patients were classified into 4 cirrhosis categories according to criteria published by Mittal et $\mathrm{al}^{44}$ : 1) level 1 evidence (very high probability) of no cirrhosis, which requires histology and imaging evidence; 2) level 2 evidence (high probability) of no cirrhosis, which lacks histology but is based on imaging and laboratory criteria; 3) confirmed cirrhosis, which is based on histological, imaging, clinical or laboratory criteria; or 4) unclassified if there was insufficient data to classify into any of the above cirrhosis categories. The AST to Platelet Ratio Index (APRI) 
Fibrosis-4 (FIB-4), and Model for End-Stage Liver Disease (MELD) were calculated for all patients using the formulas published and validated in the original papers ${ }^{46-49}$. Presence or absence of liver-related complications (ascites, hepatic encephalopathy, varices, spontaneous bacterial peritonitis, renal failure, portal vein thrombosis and hepatic hydrothorax) was collected starting the time of $\mathrm{HCC}$ diagnosis until the last documentation available in medical records.

\section{Validation of Mittal's level 2 (high probability) criteria for absence of cirrhosis}

The Mittal criteria were constructed to increase confidence in the cirrhotic or non-cirrhotic status assignment of the subgroup of patients who lacked liver histology for confirmation (Table 1) ${ }^{44}$. While the criteria for confirmed cirrhosis and level 1 evidence (very high probability) for absence of cirrhosis are clinically sound, the performance of their proposed criteria for level 2 evidence (high probability) of absence of cirrhosis has not been validated. The level 2 criteria for "no cirrhosis" consist of APRI $<1$ based on laboratory results available nearest to HCC diagnosis within 6 months before and 4 weeks after HCC diagnosis; in addition to no features suggestive of cirrhosis on abdominal imaging performed nearest to HCC diagnosis within 3 years before HCC diagnosis; and 2 of 3 test values in normal range based on laboratory results available nearest to HCC diagnosis within 6 months before and 4 weeks after $\mathrm{HCC}$ diagnosis [albumin $>3.5 \mathrm{~g} / \mathrm{L}$, platelets $200,000 / \mathrm{mL}$, or international normalized ratio (INR) $<1.1]$. By adding imaging and laboratory criteria for absence of cirrhosis to APRI, the aim was to enhance the specificity of these criteria and thus reducing the risk of misclassification when identifying non-cirrhotic status in the absence of liver histology.

To validate the level 2 Mittal criteria for the absence of cirrhosis, we randomly selected 200 patients from a large database of 1020 patients who underwent liver biopsy as part of their clinical care at Indiana University. Patients had different underlying liver disease etiologies; 100 had histologically proven cirrhosis and 100 had no histological evidence cirrhosis (16 patients with fibrosis stage 0,29 patients with fibrosis stage 1,34 patients with fibrosis stage 2 , and 21 patients with fibrosis stage 3). Applicability of level 2 non cirrhosis criteria was assessed after 
collection of laboratory data, imaging findings and evidence of complications. The area under the receiver operating characteristic curve (AUROC), sensitivity, specificity, positive predictive value (PPV), and negative predictive value (NPV) were computed for the level 2 no-cirrhosis criteria, using liver biopsy as the reference test. The performance parameters of level 2 Mittal criteria for identifying non-cirrhotic status were: AUROC $0.80(95 \% \mathrm{Cl}$ : $0.74-0.86)$, sensitivity 62.0\%, specificity 98.0\%, PPV 96.9\%, and NPV $72.0 \%$

\section{Survival status}

Patient survival was ascertained from Cancer Registries and medical records. For patients who are still alive or died with an unknown date of death, the date of last contact available in the medical record was used to define the time of censoring for the survival analysis.

\section{Statistical Methods}

Categorical variables were summarized and compared using chi-square test. Continuous variables were summarized and compared using ANOVA and t-test. Simple linear regression was used to evaluate the annual trends in terms of percentage of respective non-cirrhotic HCC, NAFLD, HBV, HCV, or alcohol etiology over the year. A sensitivity analysis was performed for the sub-cohort when patients who had level 2 no cirrhosis were excluded. HCV was considered the primary etiology of liver disease regardless of other etiology, i.e., it could be either HCV and Alcohol, HCV and HBV with or without alcohol, or HCV alone; HBV was considered the primary etiology of liver disease if no HCV was presented, i.e., HBV and Alcohol, or HBV alone.

Overall survival time was defined from the date of HCC diagnosis to the date of death, censored at the date of last contact. The overall survival probability was estimated by the Kaplan-Meier method and compared between groups using the log-rank test. A Cox proportional hazards regression model was used to evaluate the association between the risk factors and the overall survival. The following risk factors were considered for the Cox model: patient demographics [age, body mass index (BMI), sex, and race], medical history and comorbid conditions (date of HCC diagnosis, diabetes, hypertension, dyslipidemia, coronary artery disease, and peripheral 
vascular disease), laboratory values [alanine aminotransferase (ALT), aspartate aminotransferase (AST), total bilirubin, alkaline phosphatase, albumin, platelets, creatinine, INR, and alpha fetoprotein (AFP)], tumor characteristics (tumor size and anatomic stage), treatment modalities (resection, liver transplantation, catheter delivered therapy, sorafenib, stereotactic body radiation therapy (SBRT), radiofrequency ablation (RFA), microwave ablation, palliative/hospice care, other, none, and unknown), and underlying etiology (HCV, HBV, alcohol, NAFLD, and unknown/unclear). Variables that were significant at $p<0.10$ in the univariate analysis were included in a stepwise selection procedure to select which variables would be included in the final Cox multivariate regression model. Variables of clinical significance including age, BMI, sex, race, platelets, diabetes, and underlying etiology were always retained in the model. P-value $<0.05$ was considered statistically significant. All analyses were performed using SAS version 9.4 (SAS Institute; Cary, NC).

\section{RESULTS}

\section{Prevalence of non-cirrhotic HCC in the study cohort}

The study flow diagram is shown in Supplementary Figure 1. Of 6,250 identified patients, 5,144 met the inclusion criteria for HCC and had classifiable cirrhotic status; of whom $11.7 \%$ had no evidence of cirrhosis $(7.7 \%$ by level 1 and $4 \%$ by level 2 criteria) and $88.2 \%$ had confirmed cirrhosis. There were no differences between level 1 and 2 "no-cirrhosis" patients in terms of their age, sex, race, BMI, frequency of obesity, diabetes, other comorbidities or frequency of alcohol abuse (Supplementary Table 1). The majority of HCC occurred in a cirrhotic background for all specific liver diseases, including HBV and NAFLD (Table 2).

\section{Characteristics of patients with non-cirrhotic HCC}

Non-cirrhotic patients (level 1 or 2 no cirrhosis, combined) were older (64.1 \pm 14.0 vs $61.2 \pm 9.9$ years, $p<0.001)$, more frequently females $(34 \%$ vs $21 \%, p<.001)$ and Asian $(8 \%$ vs $3 \%, p$ $<0.001)$ but less frequently Black $(8 \%$ vs $12 \%$, p < 0.001$)$, compared to cirrhotic patients with 
HCC (Table 2). They had lower frequency of obesity $(22.1 \%$ vs $30.7 \%, p<0.001)$, diabetes (34.1\% vs $38.7 \%, p=0.02)$ and alcohol abuse ( $17.1 \%$ vs $46.2 \%, p<0.001)$, but higher frequency of hypertension (68.4\% vs $61.5 \%, p=0.001)$, dyslipidemia ( $38.0 \%$ vs $22.0 \%, p<0.001)$, coronary artery disease $(22.0 \%$ vs $16.7 \%, p=0.001)$, and peripheral vascular disease $(11.5 \%$ vs $7.4 \%$, $\mathrm{p}<0.001)$. As expected, non-cirrhotic patients had higher albumin $(3.9 \pm 0.6$ vs $3.3 \pm 0.7 \mathrm{~g} / \mathrm{dL}$, $\mathrm{p}<0.001)$ and platelet count $\left(278.9 \pm 118.9\right.$ vs $\left.148.4 \pm 101.4 \mathrm{~K} / \mathrm{mm}^{3}, \mathrm{p}<0.001\right)$ but lower serum total bilirubin $(1.0 \pm 2.0$ vs $2.2 \pm 3.3 \mathrm{mg} / \mathrm{dL}, \mathrm{p}<0.001)$, INR $(1.1 \pm 0.2$ vs $1.3 \pm 0.4, p<0.001)$, APRI $(1.0 \pm 1.8$ vs $3.1 \pm 6.6, p<0.001)$ and MELD scores $(8.9 \pm 3.4$ vs $12.2 \pm 5.6, p<0.001)$ and better performance status than cirrhotic patients with HCC (Table 2).

\section{Trends of non-cirrhotic HCC over the study period}

From January 2000 to June 2014, the percentage of non-cirrhotic HCC cases declined, whereas the percentage of cirrhotic HCC cases increased ( $p<0.001$; Figure 1). The same trend was observed when only level 1 no cirrhosis patients were included in this analysis $(p<0.001$; Supplementary Figure 2). We also analyzed the trends of cirrhotic and non-cirrhotic HCC evaluated per underlying liver disease etiology (Figure 2). From 2000 to 2014, there were no statistically significant changes in the HCV frequency (annual increase $0.37 \%, p=0.28$ ) and NAFLD frequency (annual increase $0.76 \%, p=0.12$ ) among non-cirrhotic HCC. In contrast, the increases were statistically significant among cirrhotic HCC (annual increase $0.96 \%$ for HCV frequency, $p<0.0001$, and $0.66 \%$ for NAFLD frequency, $p=0.003)$. Overall, there was an annual $0.74 \%$ net reduction in non-cirrhotic HCC frequency $(p<0.001)$. Cirrhotic and non-cirrhotic HCC burdens contributed by alcohol and HBV showed only significant decline for cirrhotic HCC related to HBV (Figure 2).

\section{Etiology of liver disease in non-cirrhotic HCC}

Among all HCC patients in the study cohort (Table 2), HCV was the most common liver disease associated with HCC (49\%), followed by NAFLD (14.9\%), alcohol (12.7\%) and HBV (7.4\%). 
About $12.5 \%$ of the study cohort had the underlying liver disease status documented as unclear or unknown.

Among non-cirrhotic HCC patients, NAFLD was the most common liver disease occurring in $26.3 \%$ of patients, followed by HCV in $12.1 \%$, HBV in $10 \%$, then alcohol in $7.3 \%$ of the patients. In cirrhotic HCC patients, HCV was the most common liver disease associated with HCC (53.8\%), followed by alcohol (13.5\%), NAFLD (13.4\%), and HBV (7.1\%).

\section{Tumor Characteristics in patients with non-cirrhotic HCC}

Non-cirrhotic patients had significantly larger tumors $(8.9 \pm 4.8$ vs $5.3 \pm 3.9 \mathrm{~cm}, p<0.001)$, more frequently had HCC diagnosed incidentally $(18.9 \%$ vs $11.2 \%, p<0.001)$ or for symptoms workup $(60.2 \%$ vs $55.3 \%, p=0.03)$ and less frequently as part of surveillance $(16.9 \%$ vs $29.1 \%$, $p<0.001$ ) than cirrhotic patients (Table 3). They more frequently had histological confirmation of HCC $(90.6 \%$ vs $62.3 \%, p<0.001)$. HCC in non-cirrhotic patients was more advanced (stage III or IV) $(52.3 \%$ vs $45.5 \%, p=0.002)$ and more frequently presented as single $(37.0 \%$ vs $34.4 \%$, $p<0.001)$ or large multinodular lesions $(24.7 \%$ vs $21.5 \%, p<0.001)$ with vascular invasion or extrahepatic spread $(36.3 \%$ vs $33.5 \%, p<0.001)$. Consequently, these patients less frequently presented within the Milan Criteria $(14.9 \%$ vs $39.2 \%, p<0.001)$ than cirrhotic patients.

\section{Treatment and survival of patients with non-cirrhotic HCC}

Patients with non-cirrhotic HCC more frequently underwent surgical resection $(43.6 \%$ vs $8.0 \%$, $p<0.001)$ but less frequently received liver transplantation $(2.8 \%$ vs $19.2 \%, p<0.001)$, catheter delivered therapies $(35.7 \%$ vs $42.7 \%, p=0.001)$ or palliative care-hospice services $(16.5 \%$ vs $26.8 \%, p<0.001$ ) compared to patients with cirrhotic HCC (Table 4). Patients with non-cirrhotic $\mathrm{HCC}$ had better median overall survival than patients with cirrhotic $\mathrm{HCC}[1.80$ years $(95 \% \mathrm{Cl}$ : $1.56-2.09)$ vs 1.32 years (95\% Cl: $1.25-1.39), p=0.004]$. Non-cirrhotic patient's overall survival was significantly higher at $1(63.5 \%$ vs $56.3 \%, p<0.001)$ and 3 years $(35.2 \%$ vs $30.3 \%, p=0.02)$ but not different at 5 years from diagnosis $(25.7 \%$ vs $23.4 \%, p=0.26)$ compared to patients with cirrhotic HCC (Table 5 and Figure 3). 
Risk factors associated with increased mortality in patients with non-cirrhotic HCC were INR (HR 1.96, 95\% Cl 1.21-3.18, p=0.006), AFP (HR 1.00, 95\% Cl 1.00-1.00, $p<0.001$ ), anatomic stage of HCC [ stage III vs stage I (HR 2.01, 95\% Cl 1.22-2.81, p<0.001, and stage IV vs stage I; HR 2.12, 95\% Cl 1.45-3.10, p<0.001), and hospice care (HR 1.85, 95\% Cl 1.35-2.54, p<.001), whereas albumin $(\mathrm{HR} 0.65,95 \% \mathrm{Cl} 0.51-0.83, \mathrm{p}<.001)$, surgical resection $(\mathrm{HR} 0.24,95 \% \mathrm{Cl}$ 0.17-0.34, $\mathrm{p}<.001)$ and liver transplantation ( $\mathrm{HR} 0.16,95 \% \mathrm{Cl} 0.05-0.53, \mathrm{p}=0.002)$ were associated with reduced risk of death (Table 6). The etiology of underlying liver disease did not affect mortality in patients with non-cirrhotic HCC.

\section{DISCUSSION}

In this large US multicenter study, HCC arose in non-cirrhotic liver background in nearly $12 \%$ of patients. NAFLD was the most common liver disease in these patients followed by HCV. NAFLD has contributed to both non-cirrhotic and cirrhotic HCC burden over the 14.5 year study period. However, the net effect in the cohort as of the year 2014 was increased percentage of cirrhotic HCC and a decline in non-cirrhotic HCC.

While this study and others from the US and UK have shown that NAFLD is a rapidly increasing cause of $\mathrm{HCC}^{8,9,19}$, it was not previously investigated whether NAFLD contribution is mainly through the cirrhosis-carcinogenesis pathway and/or non-cirrhotic-carcinogenesis pathway. Our study shows that NAFLD is contributing to the enlarging HCC burden via both the non-cirrhotic and cirrhotic pathways. The majority of HCC contributed by NAFLD and HCV were via the cirrhosis-HCC pathway, thus explaining the overall rise in cirrhotic HCC. The observed increase in the percentage of non-cirrhotic HCC related to NAFLD was not significant or large enough to result in increasing the total burden of non-cirrhotic HCC. This is possibly because the contribution of other liver diseases to the non-cirrhotic HCC burden was not large enough and the fraction contributed by NAFLD was not substantial as of the year 2014 . 
NAFLD (and HBV as expected) were the only etiologies significantly more common in noncirrhotic HCC. Indeed, patients with non-cirrhotic HCC were twice as likely to have NAFLD than patients with cirrhotic HCC $(26.3 \%$ vs $13.4 \%, p<0.001)$, highlighting the importance of further investigating the mechanisms of HCC development in the absence of cirrhosis in patients with NAFLD. This finding is consistent with the findings of a recent systematic analysis showing that in the absence of cirrhosis, patients with NASH have a higher risk of HCC than patients with other liver diseases ${ }^{50}$.

With the advent of effective cures, US national predictions project a decline in the contribution of $\mathrm{HCV}$ to the cirrhosis and HCC burdens and liver transplant utilization coinciding with a rise in NAFLD impact on these burdens and resources ${ }^{19,20,51,52}$. Thus, in this context, the observed significant rise in cirrhotic NAFLD HCC in this study is an important finding that confirms current AASLD guideline recommendations of surveillance for HCC in patients with NAFLD cirrhosis ${ }^{40}$. Our observation of a rise in the percentage of non-cirrhotic HCC cases related to NAFLD, albeit not statistically significant as of the end of study in 2014 , will require further follow up study of the trend in the setting of the ongoing epidemic of obesity and NAFLD.

The non-cirrhotic HCC group included significantly more women than the cirrhotic HCC group, a finding seen in another study ${ }^{53}$. The reason for this disparity is unclear but may be related to a higher prevalence of NAFLD observed in women compared to men in this study $(23.3 \%$ vs $12.4 \%, p<0.001)$.

The proportion of Asians patients was also higher in the non-cirrhotic group, probably due to higher proportion of HBV which was the underlying disease in $73.9 \%$ in non-cirrhotic Asian patients compared to $60 \%$ in cirrhotic Asian patients $(p=0.8)$.

Similar to the findings of the Mittal et al study ${ }^{44}$, slightly higher proportion of HCV patients had non-cirrhotic HCC (12.1\%) vs those with HBV (10\%). While HBV is more carcinogenic than $\mathrm{HCV}$, the prevalence and time of acquisition of HBV (at birth or childhood in endemic areas in Asia and Africa vs adulthood in the Western countries) may be the reason for this observation. 
The overall rate of non-cirrhotic HCC in this study $(11.7 \%)$ is within the range of reported rates from prior US and European studies $(6.9 \%-27.8 \%)^{9,44,53,54}$. The overall rate of non-cirrhotic HCC related to NAFLD (20.7\%) was close to that reported in recent UK $(22.8 \%)^{9}$ and German $(22.2 \%)^{55}$ studies but lower than other studies reporting these rates by disease etiology ${ }^{34-38}$. These differences may be due to population differences and varying criteria for ascertaining the cirrhotic status between studies. We used the Mittal criteria to determine cirrhotic status after we validated the Mittal level 2 criteria for absence of cirrhosis in an independent cohort and found them to be highly specific (specificity of $98 \%$ ). This should facilitate other investigators to define the absence of cirrhosis in their cohort studies with high confidence.

Non-cirrhotic patients with HCC presented at older age and with larger and more advanced HCC that was more commonly outside the Milan criteria, finding confirming those noted in other studies $53,56,57$. The significant difference in tumor size is probably due to lack of HCC surveillance in the majority of patients with non-cirrhotic HCC, who were not known to have underlying liver disease prior to the HCC presentation. Regular HCC surveillance within 2 years prior to HCC diagnosis was documented in $14.7 \%$ of non-cirrhotic patients, which is higher than the proportion of HBV patients (10\%) in this group, reflecting variability in practice patterns and adherence to guidelines. The reason for imbalance between cirrhotic and non-cirrhotic patients in frequency of metabolic and vascular comorbidities (non-cirrhotics with lower frequency of obesity and diabetes but higher frequency of hypertension, dyslipidemia and coronary artery disease), is unclear. Similar to the findings in Weinmann et al study ${ }^{55}$, patients with NAFLD and non-cirrhotic HCC in our cohort were older, more frequently females, had a higher BMI and higher frequency of metabolic and coronary artery disease (data not shown).

Non-cirrhotic patients more frequently underwent resection than liver transplantation and had better median overall survival than cirrhotic HCC. The median overall survival of non-cirrhotic patients was better than cirrhotic patients despite presenting with more advanced tumors, 
probably due to normal underlying liver function, lack of portal hypertension associated with cirrhosis and better performance status at presentation. Nevertheless, the prognosis for all patients with HCC, with or without cirrhosis, remains poor in the US at the present.

While etiology of liver disease did not affect mortality in the non-cirrhotic patients, INR, albumin, AFP, anatomic stage of $\mathrm{HCC}$, hospice care, surgical resection and liver transplantation influenced the risk of death in our study. Unlike findings of a prior single center study that assessed 143 patients with non-cirrhotic HCC specifically referred for surgical resection, age or sex did not influence the risk of death in our study ${ }^{58}$.

This study has several limitations. As with any retrospective study, some data points were missing (e.g. on performance status or histology), but our manual review of each individual patient's chart significantly reduced missing data points and allowed collection of meaningful data to permit high resolution examination of these patients and their tumors characteristics. The higher rate of unclear or unknown underlying liver etiology in non-cirrhotic patients may hint at less frequent hepatology evaluation of the underlying liver disease etiology prior to resection and locoregional therapies in this group. Another limitation is that beyond the presence or absence of cirrhotic background in the resection sample, the exact stage of fibrosis was not consistently given in the pathology reports and we failed to systematically collect such data when available. However, we augmented the our data by the use of APRI and FIB4 score, which both show that the majority of patients fell below the cirrhotic range for these tests. Similar to other studies, there is referral bias in this study as these patients were seen at tertiary care centers. Although our findings may be applicable to HCC patients seen in other tertiary centers in the US, they may not be generalizable to HCC patients seen in the community. The reliance on non-histological criteria to determine the absence of cirrhosis in a small subset (4\%) may have resulted in misclassification. However, we validated the performance of the level 2 Mittal criteria for absence of cirrhosis in an independent cohort and found these criteria to be 
highly specific. Further, when we excluded level 2 no cirrhosis patients from the analysis, the trends of cirrhotic and non-cirrhotic HCC remained the same, thus increasing the confidence in our observation.

Despite these limitations, this study has several strengths. It included the largest number of patients with non-cirrhotic HCC in the literature to date. We validated and systematically applied specific criteria to determine the cirrhotic status. The manual review of each participant's chart allowed us to collect extensive data to phenotype the patients and tumors. We did not use ICD codes or presence of comorbidities to infer the presence of NAFLD, rather we directly verified the etiology of underlying liver disease including NAFLD based on manual chart reviews. Unlike other large cohorts with a primary focus on transplantation or resection, our dataset includes four liver transplant centers and one national cancer center each offering a range of treatment modalities. Finally, the study period from 2000-2014 allowed us to assess the trends of noncirrhotic HCC and its associated liver diseases.

In conclusion, non-cirrhotic HCC account for nearly $12 \%$ of all HCC cases in this large multicenter US study. NAFLD was the most common liver disease in non-cirrhotic HCC, and a leading cause of cirrhotic HCC in this population. Although NAFLD is contributing to the rising HCC burden via both the non-cirrhotic and cirrhotic stages, its contribution to non-cirrhotic HCC burden was not significant or large enough to result in increasing the total burden of noncirrhotic HCC as of the end of this study in 2014. 


\section{References}

1. Ferlay J, Soerjomataram I, Dikshit R, et al. Cancer incidence and mortality worldwide: sources, methods and major patterns in GLOBOCAN 2012. Int $J$ Cancer. 2015;136(5):E359-386.

2. El-Serag HB, Mason AC. Rising incidence of hepatocellular carcinoma in the United States. N Engl J Med. 1999;340(10):745-750.

3. El-Serag HB. Hepatocellular carcinoma. N Engl J Med. 2011;365(12):1118-1127.

4. Ryerson AB, Eheman CR, Altekruse SF, et al. Annual Report to the Nation on the Status of Cancer, 1975-2012, featuring the increasing incidence of liver cancer. Cancer. 2016;122(9):1312-1337.

5. Petrick JL, Braunlin M, Laversanne M, Valery PC, Bray F, McGlynn KA. International trends in liver cancer incidence, overall and by histologic subtype, 1978-2007. Int J Cancer. 2016;139(7):1534-1545.

6. $\quad$ Forner A, Llovet JM, Bruix J. Hepatocellular carcinoma. Lancet. 2012;379(9822):12451255.

7. El-Serag HB, Kanwal F. Epidemiology of hepatocellular carcinoma in the United States: where are we? Where do we go? Hepatology. 2014;60(5):1767-1775.

8. Younossi ZM, Otgonsuren M, Henry L, et al. Association of nonalcoholic fatty liver disease (NAFLD) with hepatocellular carcinoma (HCC) in the United States from 2004 to 2009. Hepatology. 2015;62(6):1723-1730.

9. Dyson J, Jaques B, Chattopadyhay D, et al. Hepatocellular cancer: the impact of obesity, type 2 diabetes and a multidisciplinary team. J Hepatol. 2014;60(1):110-117.

10. Beste LA, Leipertz SL, Green PK, Dominitz JA, Ross D, loannou GN. Trends in burden of cirrhosis and hepatocellular carcinoma by underlying liver disease in US veterans, 2001-2013. Gastroenterology. 2015;149(6):1471-1482.e1475; quiz e1417-1478.

11. Park JW, Chen M, Colombo M, et al. Global patterns of hepatocellular carcinoma management from diagnosis to death: the BRIDGE Study. Liver Int. 2015;35(9):21552166.

12. Marrero JA, Fontana RJ, Su GL, Conjeevaram HS, Emick DM, Lok AS. NAFLD may be a common underlying liver disease in patients with hepatocellular carcinoma in the United States. Hepatology. 2002;36(6):1349-1354.

13. Ratziu V, Bonyhay L, Di Martino V, et al. Survival, liver failure, and hepatocellular carcinoma in obesity-related cryptogenic cirrhosis. Hepatology. 2002;35(6):1485-1493.

14. Adams LA, Lymp JF, St Sauver J, et al. The natural history of nonalcoholic fatty liver disease: a population-based cohort study. Gastroenterology. 2005;129(1):113-121.

15. Bugianesi E, Leone N, Vanni E, et al. Expanding the natural history of nonalcoholic steatohepatitis: from cryptogenic cirrhosis to hepatocellular carcinoma. Gastroenterology. 2002;123(1):134-140.

16. Shimada M, Hashimoto E, Taniai M, et al. Hepatocellular carcinoma in patients with nonalcoholic steatohepatitis. J Hepatol. 2002;37(1):154-160.

17. Sanyal AJ, Banas C, Sargeant C, et al. Similarities and differences in outcomes of cirrhosis due to nonalcoholic steatohepatitis and hepatitis C. Hepatology. 2006;43(4):682-689.

18. Ascha MS, Hanouneh IA, Lopez R, Tamimi TA, Feldstein AF, Zein NN. The incidence and risk factors of hepatocellular carcinoma in patients with nonalcoholic steatohepatitis. Hepatology. 2010;51(6):1972-1978.

19. Wong RJ, Cheung R, Ahmed A. Nonalcoholic steatohepatitis is the most rapidly growing indication for liver transplantation in patients with hepatocellular carcinoma in the U.S. Hepatology. 2014;59(6):2188-2195. 
20. Kim D, Li AA, Perumpail BJ, et al. Changing Trends in Etiology-Based and EthnicityBased Annual Mortality Rates of Cirrhosis and Hepatocellular Carcinoma in the United States. Hepatology. 2019;69(3):1064-1074.

21. El-Serag HB. CURRENT CONCEPTS Hepatocellular Carcinoma. New Engl J Med. 2011;365(12):1118-1127.

22. Bruix J, Sherman M. Management of Hepatocellular Carcinoma: An Update. Hepatology. 2011;53(3):1020-1022.

23. Bralet MP, Regimbeau JM, Pineau P, et al. Hepatocellular carcinoma occurring in nonfibrotic liver: epidemiologic and histopathologic analysis of 80 French cases. Hepatology. 2000;32(2):200-204.

24. Zen Y, Katayanagi K, Tsuneyama K, Harada K, Araki I, Nakanuma Y. Hepatocellular carcinoma arising in non-alcoholic steatohepatitis. Pathology International. 2001;51(2):127-131.

25. Bullock RE, Zaitoun AM, Aithal GP, Ryder SD, Beckingham IJ, Lobo DN. Association of non-alcoholic steatohepatitis without significant fibrosis with hepatocellular carcinoma. $J$ Hepatol. 2004;41(4):685-686.

26. Guzman G, Brunt EM, Petrovic LM, Chejfec G, Layden TJ, Cotler SJ. Does nonalcoholic fatty liver disease predispose patients to hepatocellular carcinoma in the absence of cirrhosis? Archives of pathology \& laboratory medicine. 2008;132(11):1761-1766.

27. Paradis V, Zalinski S, Chelbi E, et al. Hepatocellular carcinomas in patients with metabolic syndrome often develop without significant liver fibrosis: a pathological analysis. Hepatology. 2009;49(3):851-859.

28. Pais R, Fartoux L, Goumard C, et al. Temporal trends, clinical patterns and outcomes of NAFLD-related HCC in patients undergoing liver resection over a 20 -year period. Alimentary Pharmacology \& Therapeutics. 2017;46(9):856-863.

29. Baffy G, Brunt EM, Caldwell SH. Hepatocellular carcinoma in non-alcoholic fatty liver disease: an emerging menace. Journal of hepatology. 2012;56(6):1384-1391.

30. Stickel F, Hellerbrand C. Non-alcoholic fatty liver disease as a risk factor for hepatocellular carcinoma: mechanisms and implications. Gut. 2010;59(10):1303-1307.

31. Starley BQ, Calcagno CJ, Harrison SA. Nonalcoholic fatty liver disease and hepatocellular carcinoma: A weighty connection. Hepatology. 2010;51(5):1820-1832.

32. Malhi H, Bronk SF, Werneburg NW, Gores GJ. Free fatty acids induce JNK-dependent hepatocyte lipoapoptosis. The Journal of biological chemistry. 2006;281(17):1209312101.

33. Leung C, Yeoh SW, Patrick D, et al. Characteristics of hepatocellular carcinoma in cirrhotic and non-cirrhotic non-alcoholic fatty liver disease. World journal of gastroenterology. 2015;21(4):1189-1196.

34. Reddy SK, Steel JL, Chen HW, et al. Outcomes of curative treatment for hepatocellular cancer in nonalcoholic steatohepatitis versus hepatitis $\mathrm{C}$ and alcoholic liver disease. Hepatology. 2012;55(6):1809-1819.

35. Regimbeau JM, Colombat M, Mognol P, et al. Obesity and diabetes as a risk factor for hepatocellular carcinoma. Liver Transpl. 2004;10(2 Suppl 1):S69-73.

36. Ertle J, Dechene A, Sowa JP, et al. Non-alcoholic fatty liver disease progresses to hepatocellular carcinoma in the absence of apparent cirrhosis. Int $J$ Cancer. 2011;128(10):2436-2443.

37. Piscaglia F, Svegliati-Baroni G, Barchetti A, et al. Clinical patterns of hepatocellular carcinoma in nonalcoholic fatty liver disease: A multicenter prospective study. Hepatology. 2016;63(3):827-838.

38. Yasui K, Hashimoto E, Komorizono Y, et al. Characteristics of patients with nonalcoholic steatohepatitis who develop hepatocellular carcinoma. Clinical gastroenterology and hepatology : the official clinical practice journal of the American Gastroenterological Association. 2011;9(5):428-433; quiz e450. 
39. White DL, Kanwal F, El-Serag HB. Association between nonalcoholic fatty liver disease and risk for hepatocellular cancer, based on systematic review. Clin Gastroenterol Hepatol. 2012;10(12):1342-1359 e1342.

40. Marrero JA, Kulik LM, Sirlin CB, et al. Diagnosis, Staging, and Management of Hepatocellular Carcinoma: 2018 Practice Guidance by the American Association for the Study of Liver Diseases. Hepatology. 2018;68(2):723-750.

41. Heimbach J, Kulik LM, Finn R, et al. Aasld guidelines for the treatment of hepatocellular carcinoma. Hepatology. 2017.

42. Edge SB, Compton CC. The American Joint Committee on Cancer: the 7th edition of the AJCC cancer staging manual and the future of TNM. Ann Surg Oncol. 2010;17(6):14711474.

43. Mazzaferro V, Regalia E, Doci R, et al. Liver transplantation for the treatment of small hepatocellular carcinomas in patients with cirrhosis. N Engl J Med. 1996;334(11):693699.

44. Mittal S, El-Serag HB, Sada YH, et al. Hepatocellular Carcinoma in the Absence of Cirrhosis in United States Veterans Is Associated With Nonalcoholic Fatty Liver Disease. Clin Gastroenterol Hepatol. 2016;14(1):124-131.e121.

45. Chalasani N, Younossi Z, Lavine JE, et al. The diagnosis and management of nonalcoholic fatty liver disease: Practice guidance from the American Association for the Study of Liver Diseases. Hepatology. 2018;67(1):328-357.

46. Wai CT, Greenson JK, Fontana RJ, et al. A simple noninvasive index can predict both significant fibrosis and cirrhosis in patients with chronic hepatitis C. Hepatology (Baltimore, Md). 2003;38(2):518-526.

47. Wiesner R, Edwards E, Freeman R, et al. Model for end-stage liver disease (MELD) and allocation of donor livers. Gastroenterology. 2003;124(1):91-96.

48. Sterling RK, Lissen E, Clumeck N, et al. Development of a simple noninvasive index to predict significant fibrosis in patients with HIV/HCV coinfection. Hepatology (Baltimore, Md). 2006;43(6):1317-1325.

49. Kim BK, Kim DY, Park JY, et al. Validation of FIB-4 and comparison with other simple noninvasive indices for predicting liver fibrosis and cirrhosis in hepatitis $B$ virus-infected patients. Liver Int. 2010;30(4):546-553.

50. Stine JG, Wentworth BJ, Zimmet A, et al. Systematic review with meta-analysis: risk of hepatocellular carcinoma in non-alcoholic steatohepatitis without cirrhosis compared to other liver diseases. Aliment Pharmacol Ther. 2018;48(7):696-703.

51. Ahmed O, Liu L, Gayed A, et al. The Changing Face of Hepatocellular Carcinoma: Forecasting Prevalence of Nonalcoholic Steatohepatitis and Hepatitis C Cirrhosis. Journal of clinical and experimental hepatology. 2019;9(1):50-55.

52. Wong RJ, Aguilar M, Cheung R, et al. Nonalcoholic steatohepatitis is the second leading etiology of liver disease among adults awaiting liver transplantation in the United States. Gastroenterology. 2015;148(3):547-555.

53. Schutte K, Schulz C, Poranzke J, et al. Characterization and prognosis of patients with hepatocellular carcinoma (HCC) in the non-cirrhotic liver. BMC Gastroenterol. 2014;14:117.

54. Stroffolini $T$, Andreone $P$, Andriulli A, et al. Characteristics of hepatocellular carcinoma in Italy. J Hepatol. 1998;29(6):944-952.

55. Weinmann A, Alt Y, Koch S, et al. Treatment and survival of non-alcoholic steatohepatitis associated hepatocellular carcinoma. BMC Cancer. 2015;15(1):210.

56. Mohamad B, Shah V, Onyshchenko M, et al. Characterization of hepatocellular carcinoma (HCC) in non-alcoholic fatty liver disease (NAFLD) patients without cirrhosis. Hepatol Int. 2016;10(4):632-639. 
57. Wong CR, Njei B, Nguyen MH, Nguyen A, Lim JK. Survival after treatment with curative intent for hepatocellular carcinoma among patients with vs without non-alcoholic fatty liver disease. Alimentary Pharmacology \& Therapeutics. 2017;46(11-12):1061-1069.

58. Smoot RL, Nagorney DM, Chandan VS, et al. Resection of hepatocellular carcinoma in patients without cirrhosis. Br J Surg. 2011;98(5):697-703. 


\section{Figure Legends}

\section{Figure 1:}

Panel A: Non-cirrhotic HCC: Percentage of non-cirrhotic patients from 2000 to 2014

Panel B: Cirrhotic HCC: Percentage of cirrhotic patients from 2000 to 2014

\section{Figure 2:}

Time Trends of the Percentage of Non-Cirrhotic and Cirrhotic HCC per Underlying Liver Disease Etiology

\section{Figure 3:}

Survival of HCC patients with and without underlying cirrhosis 
Table 1. Mittal's definitions for classification of cirrhosis categories

\begin{tabular}{|c|c|}
\hline Cirrhosis Category & Definition \\
\hline $\begin{array}{l}\text { Level } 1 \text { evidence of no } \\
\text { cirrhosis (very high } \\
\text { probability) }\end{array}$ & $\begin{array}{l}\text { No evidence of cirrhosis on resection specimen or liver biopsy performed } \\
\text { within } 1 \text { year before or at time of HCC diagnosis. } \\
\text { AND } \\
\text { No features suggestive of cirrhosis on abdominal imaging available } \\
\text { nearest to HCC diagnosis within } 3 \text { years before HCC diagnosis. }\end{array}$ \\
\hline $\begin{array}{l}\text { Level } 2 \text { evidence of no } \\
\text { cirrhosis (high } \\
\text { probability) }\end{array}$ & $\begin{array}{l}\text { APRI }<1 \text { based on laboratory results available nearest to HCC diagnosis } \\
\text { within } 6 \text { months before and } 4 \text { weeks after HCC diagnosis. } \\
\text { AND } \\
\text { No features suggestive of cirrhosis on abdominal imaging performed } \\
\text { nearest to HCC diagnosis within } 3 \text { years before HCC diagnosis. } \\
\text { AND } \\
\text { Two of } 3 \text { test values in normal range based on laboratory results } \\
\text { available nearest to HCC diagnosis within } 6 \text { months before and } 4 \text { weeks } \\
\text { after HCC diagnosis }(\text { albumin }>3.5 \mathrm{~g} / \mathrm{L} \text {, platelets }>200,000 / \mathrm{mL} \text {, or } \\
\text { international normalized ratio }<1.1 \text { ). }\end{array}$ \\
\hline Confirmed Cirrhosis & $\begin{array}{l}\text { Documented cirrhosis on resection specimen or liver biopsy performed } \\
\text { any time before or at time of HCC diagnosis. } \\
\text { OR } \\
\text { Features suggestive of cirrhosis on abdominal imaging performed } \\
\text { nearest to HCC diagnosis within } 3 \text { years before HCC diagnosis. } \\
\frac{\text { OR }}{\text { Documented presence of ascites, varices, or hepatic encephalopathy. }} \\
\text { OR } \\
\text { Abnormal values on } 2 \text { of } 3 \text { laboratory tests available nearest to HCC } \\
\text { diagnosis within } 6 \text { months before and } 4 \text { weeks after HCC diagnosis } \\
\text { (albumin }<3.0 \mathrm{~g} / \mathrm{L} \text {, platelets }<200,000 \mathrm{~mL} \text {, international normalized ratio } \\
>1.1) \text {. }\end{array}$ \\
\hline Unclassified & Insufficient information to classify in any cirrhosis category. \\
\hline
\end{tabular}

From Mittal et $\mathrm{al}^{44}$. Right to use table obtained from Elsevier. 
Table 2: Characteristics of the patients with hepatocellular carcinoma with and without underlying cirrhosis

\begin{tabular}{|c|c|c|c|}
\hline \multirow[t]{2}{*}{ Variable } & \multicolumn{2}{|c|}{ Cirrhosis } & \multirow[t]{2}{*}{ p-value } \\
\hline & $\begin{array}{c}\text { No } \\
N=605\end{array}$ & $\begin{array}{c}\text { Yes } \\
\mathrm{N}=4,539\end{array}$ & \\
\hline Age (Years) & $64.1 \pm 14.0$ & $61.2 \pm 9.9$ & $<0.001$ \\
\hline Male Sex & $400(66.1 \%)$ & $3,597(79.2 \%)$ & $<0.001$ \\
\hline \multicolumn{4}{|l|}{ Race } \\
\hline - White & $420(70.0 \%)$ & $3,149(70.4 \%)$ & \multirow{5}{*}{$<0.001$} \\
\hline - Black & $50(8.3 \%)$ & $556(12.4 \%)$ & \\
\hline - Hispanic & $59(9.8 \%)$ & $452(10.1 \%)$ & \\
\hline - Asian & $46(7.7 \%)$ & $140(3.1 \%)$ & \\
\hline - Other & $25(4.2 \%)$ & $174(3.9 \%)$ & \\
\hline \multicolumn{4}{|l|}{ Center* } \\
\hline Atrium Health & $55(9.6 \%)$ & $509(89 \%)$ & \multirow[b]{5}{*}{$<0.001$} \\
\hline Columbia & $61(11.3 \%)$ & $470(87.2 \%)$ & \\
\hline Indiana University & $135(10.8 \%)$ & $1054(84.3 \%)$ & \\
\hline MD Anderson & $329(15.6 \%)$ & $1728(82.1 \%)$ & \\
\hline Vanderbilt & $25(2.9 \%)$ & $778(90.3 \%)$ & \\
\hline BMl (kg/m2) & $27.3 \pm 6.1$ & $28.6 \pm 6.0$ & $<0.001$ \\
\hline Obesity & $134(22.1 \%)$ & $1,392(30.7 \%)$ & $<0.001$ \\
\hline Diabetes & $205(34.1 \%)$ & $1,749(38.7 \%)$ & 0.02 \\
\hline Hypertension & $412(68.4 \%)$ & $2,777(61.5 \%)$ & 0.001 \\
\hline Dyslipidemia & $229(38.0 \%)$ & $992(22.0 \%)$ & $<0.001$ \\
\hline Coronary Artery Disease & $132(22.0 \%)$ & $752(16.7 \%)$ & 0.001 \\
\hline $\begin{array}{l}\text { Peripheral Vascular } \\
\text { Disease }\end{array}$ & $69(11.5 \%)$ & $332(7.4 \%)$ & $<0.001$ \\
\hline History of Alcohol Abuse & $102(17.1 \%)$ & $2,075(46.2 \%)$ & $<0.001$ \\
\hline HIV Positive & $4(0.7 \%)$ & $55(1.2 \%)$ & 0.34 \\
\hline Total Bilirubin (mg/dL) & $1.0 \pm 2.0$ & $2.2 \pm 3.3$ & $<0.001$ \\
\hline Albumin (g/dL) & $3.9 \pm 0.6$ & $3.3 \pm 0.7$ & $<0.001$ \\
\hline Platelets $\left(\mathrm{K} / \mathrm{mm}^{3}\right)$ & $278.9 \pm 118.9$ & $148.4 \pm 101.4$ & $<0.001$ \\
\hline Creatinine (mg/dL) & $1.0 \pm 0.7$ & $1.1 \pm 0.8$ & 0.72 \\
\hline INR & $1.1 \pm 0.2$ & $1.3 \pm 0.4$ & $<0.001$ \\
\hline MELD Score & NA & $12.2 \pm 5.6$ & \\
\hline APRI Score & $1.0 \pm 1.8$ & $3.1 \pm 6.6$ & $<0.001$ \\
\hline \multicolumn{4}{|l|}{ APRI Category } \\
\hline$-<1.0$ & $450(78.5 \%)$ & $1,077(25.8 \%)$ & \multirow{3}{*}{$<0.001$} \\
\hline$-1.0-2.0$ & $77(13.4 \%)$ & $1,143(27.4 \%)$ & \\
\hline$->2.0$ & $46(8.0 \%)$ & $1,950(46.8 \%)$ & \\
\hline
\end{tabular}




\begin{tabular}{|c|c|c|c|}
\hline \multirow[t]{2}{*}{ Variable } & \multicolumn{2}{|c|}{ Cirrhosis } & \multirow[t]{2}{*}{$p$-value } \\
\hline & $\begin{array}{c}\text { No } \\
N=605\end{array}$ & $\begin{array}{c}\text { Yes } \\
\mathrm{N}=4,539\end{array}$ & \\
\hline \multicolumn{4}{|l|}{ FIB-4 Category } \\
\hline$-<1.60$ & $194(34.4 \%)$ & $212(5.1 \%)$ & \multirow{3}{*}{$<.0001$} \\
\hline$-1.60-3.60$ & $255(45.2 \%)$ & $874(21.1 \%)$ & \\
\hline$->3.60$ & $115(20.4 \%)$ & $3,066(73.8 \%)$ & \\
\hline \multicolumn{4}{|l|}{ Performance Status } \\
\hline - 0 (KPS 90 or 100$)$ & $190(49.2 \%)$ & $799(38.4 \%)$ & \multirow{5}{*}{$<0.001$} \\
\hline-1 (KPS 70 or 80$)$ & $130(33.7 \%)$ & $773(37.1 \%)$ & \\
\hline - 2 (KPS 50 or 60$)$ & $48(12.4 \%)$ & $313(15.0 \%)$ & \\
\hline - 3 (KPS 30 or 40$)$ & $16(4.1 \%)$ & $164(7.9 \%)$ & \\
\hline - 4 (KPS 10 or 20$)$ & $2(0.5 \%)$ & $33(1.6 \%)$ & \\
\hline \multicolumn{4}{|l|}{ Underlying liver disease } \\
\hline - AIH/PBC/PSC & $4(0.7 \%)$ & $72(1.6 \%)$ & \multirow{11}{*}{$<0.001$} \\
\hline - Alcohol alone & $44(7.3 \%)$ & $611(13.5 \%)$ & \\
\hline - HBV + Alcohol & $10(1.7 \%)$ & $59(1.3 \%)$ & \\
\hline - HBV alone & $50(8.3 \%)$ & $265(5.8 \%)$ & \\
\hline - HC/A1ATD & $3(0.5 \%)$ & $78(1.7 \%)$ & \\
\hline - HCV + Alcohol & $11(1.8 \%)$ & $1,053(23.2 \%)$ & \\
\hline - HCV + HBV (+/- alcohol) & $10(1.7 \%)$ & $178(3.9 \%)$ & \\
\hline - HCV alone & $52(8.6 \%)$ & $1,211(26.7 \%)$ & \\
\hline - NAFLD & $159(26.3 \%)$ & $608(13.4 \%)$ & \\
\hline - Rare etiologies & $5(0.8 \%)$ & $16(0.4 \%)$ & \\
\hline - Unclear/Unknown & $257(42.5 \%)$ & $388(8.5 \%)$ & \\
\hline
\end{tabular}

Abbreviations: BMI: body mass index, HIV: human immunodeficiency virus, INR: international normalized ratio, MELD: Model for End-Stage Liver Disease, APRI: AST to Platelet Ratio Index, $\mathrm{HCV}$ : hepatitis $\mathrm{C}$ virus, AlH: autoimmune hepatitis. PBC: primary biliary cholangitis, PSC:

primary sclerosing cholangitis, HC: hemochromatosis, A1ATD: alpha-1-antitrypsin deficiency, NA: not applicable, NAFLD: non-alcoholic fatty liver disease. ${ }^{*}$ Remaining $\%$ in each center data indicate $\%$ with unclassified cirrhotic status. 
Table 3: Tumor characteristics in patients with and without underlying cirrhosis

\begin{tabular}{|c|c|c|c|}
\hline \multirow[b]{2}{*}{ Variable } & \multicolumn{2}{|c|}{ Cirrhosis } & \multirow[b]{2}{*}{ p-value } \\
\hline & $\begin{array}{c}\mathrm{No} \\
\mathrm{N}=605\end{array}$ & $\begin{array}{c}\text { Yes } \\
\mathrm{N}=4,539\end{array}$ & \\
\hline Tumor Size $(\mathrm{cm})$ & $8.9 \pm 4.8$ & $5.3 \pm 3.9$ & $<.001$ \\
\hline \multicolumn{4}{|l|}{ AFP Category } \\
\hline$-<20$ & $242(45.1 \%)$ & $1,711(42.7 \%)$ & \multirow{3}{*}{0.01} \\
\hline$-20-200$ & $96(17.9 \%)$ & $942(23.5 \%)$ & \\
\hline$->200$ & $199(37.1 \%)$ & $1,358(33.9 \%)$ & \\
\hline - Part of surveillance & $84(16.9 \%)$ & $1,075(29.1 \%)$ & $<0.001$ \\
\hline - Incidental & $94(18.9 \%)$ & $416(11.2 \%)$ & $<0.001$ \\
\hline - Symptoms work-up & $299(60.2 \%)$ & $2,045(55.3 \%)$ & 0.03 \\
\hline - Other & $4(0.8 \%)$ & $6(0.2 \%)$ & 0.005 \\
\hline - NA/Unknown & $17(3.4 \%)$ & $189(5.1 \%)$ & 0.10 \\
\hline \multicolumn{4}{|c|}{ Regular Surveillance within 2 Years before HCC? } \\
\hline - Yes & $73(14.7 \%)$ & $1206(32.5 \%)$ & \multirow{2}{*}{$<0.001$} \\
\hline - Unknown & $160(32.3 \%)$ & $1432(38.6 \%)$ & \\
\hline \multicolumn{4}{|l|}{ Method of Diagnosis } \\
\hline - Histology & $548(90.6 \%)$ & $2828(62.3 \%)$ & $<.001$ \\
\hline - Imaging & $568(93.9 \%)$ & $4257(93.8 \%)$ & 0.92 \\
\hline - Other & $5(0.8 \%)$ & $20(0.4 \%)$ & 0.19 \\
\hline - Unknown & $0(0.0 \%)$ & $4(0.1 \%)$ & 0.46 \\
\hline \multicolumn{4}{|l|}{ Anatomic Stage } \\
\hline - Stage I & $184(33.6 \%)$ & $1278(31.9 \%)$ & \multirow{7}{*}{$<0.001$} \\
\hline - Stage II & $77(14.1 \%)$ & $905(22.6 \%)$ & \\
\hline - Stage IIIA & $81(14.8 \%)$ & $414(10.3 \%)$ & \\
\hline - Stage IIIB & $54(9.9 \%)$ & $619(15.4 \%)$ & \\
\hline - Stage IIIC & $16(2.9 \%)$ & $44(1.1 \%)$ & \\
\hline - Stage IVA & $31(5.7 \%)$ & $210(5.2 \%)$ & \\
\hline - Stage IVB & $104(19.0 \%)$ & $537(13.4 \%)$ & \\
\hline \multicolumn{4}{|c|}{ Anatomic Stage Category } \\
\hline - Stage I or II & $261(47.7 \%)$ & $2183(54.5 \%)$ & \multirow{2}{*}{0.002} \\
\hline - Stage III or IV & $286(52.3 \%)$ & $1824(45.5 \%)$ & \\
\hline \multicolumn{4}{|l|}{ Tumor Differentiation } \\
\hline - Well & $139(29.8 \%)$ & $757(33.1 \%)$ & \multirow{4}{*}{0.056} \\
\hline - Moderate & $206(44.2 \%)$ & $1066(46.6 \%)$ & \\
\hline - Poor & $117(25.1 \%)$ & $450(19.7 \%)$ & \\
\hline $\begin{array}{l}\text { - Undifferentiated / } \\
\text { anaplastic }\end{array}$ & $4(0.9 \%)$ & $15(0.7 \%)$ & \\
\hline Tumor Stage & & & \\
\hline
\end{tabular}




\begin{tabular}{|c|c|c|c|}
\hline \multirow[b]{2}{*}{ Variable } & \multicolumn{2}{|c|}{ Cirrhosis } & \multirow[b]{2}{*}{ p-value } \\
\hline & $\begin{array}{c}\text { No } \\
N=605\end{array}$ & $\begin{array}{c}\text { Yes } \\
\mathrm{N}=4,539\end{array}$ & \\
\hline - Single & $222(37.0 \%)$ & $1545(34.4 \%)$ & \multirow{4}{*}{$<0.001$} \\
\hline-3 tumors $<3 \mathrm{~cm}$ & $12(2.0 \%)$ & $478(10.6 \%)$ & \\
\hline - Large multinodular & $148(24.7 \%)$ & $966(21.5 \%)$ & \\
\hline $\begin{array}{l}\text { - Vascular invasion or } \\
\text { extrahepatic spread }\end{array}$ & $218(36.3 \%)$ & $1503(33.5 \%)$ & \\
\hline $\begin{array}{l}\text { Tumor within Milan } \\
\text { Criteria }\end{array}$ & $90(14.9 \%)$ & $1774(39.2 \%)$ & $<0.001$ \\
\hline
\end{tabular}

Abbreviations: AFP: Alfa fetoprotein. 
Table 4: Treatment modalities offered to patients with HCC, stratified according to Cirrhosis Status

\begin{tabular}{|c|c|c|c|}
\hline \multirow[b]{2}{*}{ Variable } & \multicolumn{2}{|c|}{ Cirrhosis } & \multirow[b]{2}{*}{ p-value } \\
\hline & $\begin{array}{c}\text { No } \\
N=605\end{array}$ & $\begin{array}{c}\text { Yes } \\
\mathrm{N}=4,539\end{array}$ & \\
\hline \multicolumn{4}{|l|}{ Treatment Modalities } \\
\hline - Resection & $264(43.6 \%)$ & $362(8.0 \%)$ & $<0.001$ \\
\hline - Liver Transplantation & $17(2.8 \%)$ & $873(19.2 \%)$ & $<0.001$ \\
\hline $\begin{array}{l}\text { - Catheter Delivered } \\
\text { Therapy }\end{array}$ & $216(35.7 \%)$ & $1,939(42.7 \%)$ & 0.001 \\
\hline - Sorafenib & $131(21.7 \%)$ & $921(20.3 \%)$ & 0.43 \\
\hline - SBRT & $54(8.9 \%)$ & $348(7.7 \%)$ & 0.27 \\
\hline $\begin{array}{l}\text { - RFA and/or Microwave } \\
\text { Ablation }\end{array}$ & $53(8.8 \%)$ & $502(11.1 \%)$ & 0.08 \\
\hline - Palliative/Hospice Care & $100(16.5 \%)$ & $1,218(26.8 \%)$ & $<0.001$ \\
\hline - Other & $83(13.7 \%)$ & $313(6.9 \%)$ & $<0.001$ \\
\hline - None & $19(3.1 \%)$ & $246(5.4 \%)$ & 0.01 \\
\hline - Unknown & $42(6.9 \%)$ & $271(6.0 \%)$ & 0.34 \\
\hline
\end{tabular}

Abbreviations: SBRT: stereotactic body radiation therapy; RFA: radiofrequency ablation 
Table 5: Survival of Patients with HCC with and without underlying cirrhosis

\begin{tabular}{|l|c|c|c|}
\hline \multirow{2}{*}{ Survival } & \multicolumn{2}{|c|}{ Cirrhosis } & \multirow{2}{*}{ p-value } \\
\cline { 2 - 3 } & $\begin{array}{c}\text { No } \\
\mathbf{N = 6 0 5}\end{array}$ & $\begin{array}{c}\text { Yes } \\
\mathbf{N = 4 , 5 3 9}\end{array}$ & -vilu \\
\hline $\begin{array}{l}\text { Overall (years), median } \\
(95 \% \text { Cl) }\end{array}$ & 1.80 & 1.32 & 0.004 \\
\hline One Year & $(1.56-2.09)$ & $(1.25-1.39)$ & $<.001$ \\
\hline Three Year & $63.5 \%$ & $56.3 \%$ & 0.02 \\
\hline Five Year & $35.2 \%$ & $30.3 \%$ & 0.26 \\
\hline
\end{tabular}

Abbreviations: $\mathrm{Cl}$ : Confidence Interval. 
Table 6: Variables associated with mortality among patients with non-cirrhotic HCC

\begin{tabular}{|l|c|c|c|}
\hline \multicolumn{1}{|c|}{ Variable } & HR & $\mathbf{9 5 \%} \mathbf{C l}$ & p-value \\
\hline Age at Diagnosis & 1.00 & $0.99-1.01$ & 0.67 \\
\hline BMI at Diagnosis & 0.99 & $0.96-1.01$ & 0.22 \\
\hline Platelets & 1.00 & $1.00-1.00$ & 0.12 \\
\hline INR & 1.96 & $1.21-3.18$ & $\mathbf{0 . 0 0 6}$ \\
\hline Albumin & 0.65 & $0.51-0.83$ & $<\mathbf{0 . 0 0 1}$ \\
\hline AFP & 1.00 & $1.00-1.00$ & $<0.001$ \\
\hline Female Sex & 1.23 & $0.92-1.66$ & 0.16 \\
\hline Race & \multicolumn{3}{|l|}{} \\
\hline Asian vs White & 0.84 & $0.37-1.95$ & 0.69 \\
\hline Black vs White & 0.80 & $0.50-1.29$ & 0.36 \\
\hline Hispanic vs White & 1.11 & $0.76-1.63$ & 0.58 \\
\hline Other vs White & 1.11 & $0.58-2.14$ & 0.75 \\
\hline Diabetes & 1.20 & $0.89-1.60$ & 0.22 \\
\hline Anatomic Stage & \multicolumn{3}{|l|}{} \\
\hline Stage II vs Stage I & 0.88 & $0.55-1.40$ & 0.58 \\
\hline Stage III vs Stage I & 2.01 & $1.44-2.81$ & $<\mathbf{0 . 0 0 1}$ \\
\hline Stage IV vs Stage I & 2.12 & $1.45-3.10$ & $<\mathbf{0 . 0 0 1}$ \\
\hline Resection & 0.24 & $0.17-0.34$ & $<\mathbf{0 . 0 0 1}$ \\
\hline Liver Transplantation & 0.16 & $0.05-0.53$ & $\mathbf{0 . 0 0 2}$ \\
\hline Palliative/Hospice Care & 1.85 & $1.35-2.54$ & $<\mathbf{0 . 0 0 1}$ \\
\hline Etiologies & 1.02 & $0.64-1.63$ & 0.92 \\
\hline Alcohol Alone vs Unclear/Unknown & 1.60 & $0.67-3.81$ & 0.29 \\
\hline HBV vs Unclear/Unknown & 1.24 & $0.80-1.91$ & 0.33 \\
\hline HCV vs Unclear/Unknown & 0.98 & $0.71-1.36$ & 0.92 \\
\hline NAFLD vs Unclear/Unknown
\end{tabular}

Abbreviations: BMl: body mass index; INR: international normalized ratio; AFP: Alfa fetoprotein; HR: Hazard Ratio; Cl: Confidence Interval. 


\section{Supplemental Material}

\section{Supplemental Table 1}

Characteristics of patients with HCC without underlying cirrhosis, separated based on Level 1 vs. Level 2 criteria for the absence of cirrhosis

\section{Supplemental Figure 1:}

Study Flow Diagram

\section{Supplemental Figure 2:}

Time Trends of the Percentage of Non-Cirrhotic (Level 1 Criteria)) and Cirrhotic HCC in the Overall Cohort

\section{Panel A:}

Non-cirrhotic HCC by level 1 criteria: Percentage of non-cirrhotic patients by level 1 criteria from 2000 to 2014

\section{Panel B:}

Cirrhotic HCC: Percentage of patients with $\mathrm{HCC}$ and underlying cirrhosis over time 
Supplementary Table 1: Characteristics of patients with HCC without underlying cirrhosis, separated based on Level 1 vs. Level 2 criteria for the absence of cirrhosis

\begin{tabular}{|c|c|c|c|c|}
\hline \multirow[b]{2}{*}{ Variable } & \multirow[b]{2}{*}{$\begin{array}{l}\text { Overall } \\
N=605\end{array}$} & \multicolumn{2}{|c|}{ Evidence of No Cirrhosis } & \multirow[b]{2}{*}{$p$-value } \\
\hline & & $\begin{array}{l}\text { Level } 1 \\
\mathrm{~N}=397\end{array}$ & $\begin{array}{l}\text { Level } 2 \\
\mathrm{~N}=208\end{array}$ & \\
\hline Age (Years) & $64.1 \pm 14.0$ & $63.3 \pm 14.1$ & $65.5 \pm 13.7$ & 0.06 \\
\hline Males & $400(66.1 \%)$ & $264(66.5 \%)$ & $136(65.4 \%)$ & 0.78 \\
\hline \multicolumn{5}{|l|}{ Race } \\
\hline - White & $420(70.0 \%)$ & $279(71.0 \%)$ & $141(68.1 \%)$ & \multirow{5}{*}{0.52} \\
\hline - Black & $50(8.3 \%)$ & $35(8.9 \%)$ & $15(7.2 \%)$ & \\
\hline - Hispanic & $59(9.8 \%)$ & $33(8.4 \%)$ & $26(12.6 \%)$ & \\
\hline - Asian & $46(7.7 \%)$ & $29(7.4 \%)$ & $17(8.2 \%)$ & \\
\hline - Other & $25(4.2 \%)$ & $17(4.3 \%)$ & $8(3.9 \%)$ & \\
\hline $\mathrm{BMI}\left(\mathrm{kg} / \mathrm{m}^{2}\right)$ & $27.3 \pm 6.1$ & $27.4 \pm 6.3$ & $27.1 \pm 5.9$ & 0.53 \\
\hline Obesity & $134(22.1 \%)$ & $85(21.4 \%)$ & $49(23.6 \%)$ & 0.54 \\
\hline Diabetes & $205(34.1 \%)$ & $135(34.2 \%)$ & $70(33.8 \%)$ & 0.92 \\
\hline Hypertension & $412(68.4 \%)$ & $267(67.6 \%)$ & $145(70.0 \%)$ & 0.53 \\
\hline Dyslipidemia & $229(38.0 \%)$ & $155(39.2 \%)$ & $74(35.7 \%)$ & 0.40 \\
\hline Coronary Artery Disease & $132(22.0 \%)$ & $79(20.1 \%)$ & $53(25.6 \%)$ & 0.11 \\
\hline Peripheral Vascular Disease & $69(11.5 \%)$ & $41(10.4 \%)$ & $28(13.6 \%)$ & 0.24 \\
\hline History of Alcohol Abuse & $102(17.1 \%)$ & $61(15.6 \%)$ & $41(19.9 \%)$ & 0.17 \\
\hline ALT (units/L) & $65.2 \pm 82.1$ & $73.2 \pm 90.8$ & $50.3 \pm 59.6$ & 0.001 \\
\hline AST (units/L) & $88.1 \pm 149.0$ & $101.7 \pm 180.3$ & $63.2 \pm 50.4$ & 0.003 \\
\hline Total Bilirubin (mg/dL) & $1.0 \pm 2.0$ & $1.1 \pm 2.4$ & $0.9 \pm 1.1$ & 0.19 \\
\hline $\begin{array}{l}\text { Alkaline Phosphatase } \\
\text { (units/L) }\end{array}$ & $178.8 \pm 214.0$ & $186.3 \pm 247.4$ & $164.7 \pm 130.5$ & 0.24 \\
\hline Albumin (g/dL) & $3.9 \pm 0.6$ & $3.9 \pm 0.6$ & $3.9 \pm 0.6$ & 0.65 \\
\hline Platelets $\left(\mathrm{K} / \mathrm{mm}^{3}\right)$ & $278.9 \pm 118.9$ & $267.1 \pm 116.3$ & $300.8 \pm 120.8$ & 0.001 \\
\hline Creatinine (mg/dL) & $1.0 \pm 0.7$ & $1.0 \pm 0.8$ & $1.1 \pm 0.7$ & 0.65 \\
\hline INR & $1.1 \pm 0.2$ & $1.1 \pm 0.2$ & $1.1 \pm 0.3$ & 0.6496 \\
\hline $\operatorname{AFP}(\mathrm{ng} / \mathrm{mL})$ & $\begin{array}{l}27,536.6 \pm \\
149,888.1\end{array}$ & $\begin{array}{l}28,778.2 \pm \\
174611.7\end{array}$ & $\begin{array}{l}25,287.5 \pm \\
89,493.5\end{array}$ & 0.79 \\
\hline MELD Score & $8.9 \pm 3.4$ & $8.9 \pm 3.5$ & $8.8 \pm 3.2$ & 0.74 \\
\hline APRI Score & $1.0 \pm 1.8$ & $1.2 \pm 2.2$ & $0.6 \pm 0.4$ & $<.0001$ \\
\hline \multicolumn{5}{|l|}{ APRI Category } \\
\hline$-<1.0$ & $450(78.5 \%)$ & $259(70.2 \%)$ & $191(93.6 \%)$ & \multirow{3}{*}{$<0.001$} \\
\hline$-1.0-2.0$ & $77(13.4 \%)$ & $67(18.2 \%)$ & $10(4.9 \%)$ & \\
\hline$->2.0$ & $46(8.0 \%)$ & $43(11.7 \%)$ & $3(1.5 \%)$ & \\
\hline \multicolumn{5}{|l|}{ Performance Status } \\
\hline - 0 (KPS 90 or 100$)$ & $190(49.2 \%)$ & $141(55.1 \%)$ & $49(37.7 \%)$ & 0.006 \\
\hline
\end{tabular}




\begin{tabular}{|c|c|c|c|c|}
\hline \multirow[b]{2}{*}{ Variable } & \multirow[b]{2}{*}{$\begin{array}{l}\text { Overall } \\
\mathrm{N}=605\end{array}$} & \multicolumn{2}{|c|}{ Evidence of No Cirrhosis } & \multirow[b]{2}{*}{ p-value } \\
\hline & & $\begin{array}{l}\text { Level } 1 \\
\mathrm{~N}=397\end{array}$ & $\begin{array}{l}\text { Level } 2 \\
\mathrm{~N}=208\end{array}$ & \\
\hline-1 (KPS 70 or 80$)$ & $130(33.7 \%)$ & $75(29.3 \%)$ & $55(42.3 \%)$ & \\
\hline-2 (KPS 50 or 60$)$ & $48(12.4 \%)$ & $31(12.1 \%)$ & $17(13.1 \%)$ & \\
\hline-3 (KPS 30 or 40$)$ & $16(4.1 \%)$ & $9(3.5 \%)$ & $7(5.4 \%)$ & \\
\hline-4 (KPS 10 or 20$)$ & $2(0.5 \%)$ & & $2(1.5 \%)$ & \\
\hline \multicolumn{5}{|l|}{ Underlying liver disease } \\
\hline - AIH/PBC/PSC & $4(0.7 \%)$ & $4(1.0 \%)$ & $0(0.0 \%)$ & \multirow{11}{*}{0.01} \\
\hline - Alcohol alone & $44(7.3 \%)$ & $24(6.0 \%)$ & $20(9.6 \%)$ & \\
\hline - HBV + Alcohol & $10(1.7 \%)$ & $6(1.5 \%)$ & $4(1.9 \%)$ & \\
\hline - HBV alone & $50(8.3 \%)$ & $34(8.6 \%)$ & $16(7.7 \%)$ & \\
\hline - HC/A1ATD & $3(0.5 \%)$ & $1(0.3 \%)$ & $2(1.0 \%)$ & \\
\hline - HCV + Alcohol & $11(1.8 \%)$ & $7(1.8 \%)$ & $4(1.9 \%)$ & \\
\hline$-\mathrm{HCV}+\mathrm{HBV}$ (+/- alcohol) & $10(1.7 \%)$ & $6(1.5 \%)$ & $4(1.9 \%)$ & \\
\hline - HCV alone & $52(8.6 \%)$ & $37(9.3 \%)$ & $15(7.2 \%)$ & \\
\hline - NAFLD & $159(26.3 \%)$ & $123(31.0 \%)$ & $36(17.3 \%)$ & \\
\hline - Rare etiologies & $5(0.8 \%)$ & $4(1.0 \%)$ & $1(0.5 \%)$ & \\
\hline - Unclear/Unknown & $257(42.5 \%)$ & $151(38.0 \%)$ & $106(51.0 \%)$ & \\
\hline Tumor Size & $8.9 \pm 4.8$ & $8.9 \pm 4.9$ & $9.1 \pm 4.8$ & 0.61 \\
\hline \multicolumn{5}{|l|}{ Anatomic Stage Category } \\
\hline - Stage I or II & $261(47.7 \%)$ & $192(54.4 \%)$ & $69(35.6 \%)$ & \multirow{2}{*}{$<0.001$} \\
\hline - Stage III or IV & $286(52.3 \%)$ & $161(45.6 \%)$ & $125(64.4 \%)$ & \\
\hline \multicolumn{5}{|l|}{ Tumor Differentiation } \\
\hline- Well & $139(29.8 \%)$ & $93(28.6 \%)$ & $46(32.6 \%)$ & \multirow{4}{*}{0.01} \\
\hline - Moderate & $206(44.2 \%)$ & $158(48.6 \%)$ & $48(34.0 \%)$ & \\
\hline - Poor & $117(25.1 \%)$ & $71(21.8 \%)$ & $46(32.6 \%)$ & \\
\hline - Undifferentiated / anaplastic & $4(0.9 \%)$ & $3(0.9 \%)$ & $1(0.7 \%)$ & \\
\hline \multicolumn{5}{|l|}{ Tumor Stage } \\
\hline - Single & $222(37.0 \%)$ & $164(41.3 \%)$ & $58(28.6 \%)$ & \multirow{4}{*}{$<0.001$} \\
\hline-3 tumors $<3 \mathrm{~cm}$ & $12(2.0 \%)$ & $10(2.5 \%)$ & $2(1.0 \%)$ & \\
\hline - Large multinodular & $148(24.7 \%)$ & $102(25.7 \%)$ & $46(22.7 \%)$ & \\
\hline $\begin{array}{l}\text { - Vascular invasion or } \\
\text { extrahepatic spread }\end{array}$ & $218(36.3 \%)$ & $121(30.5 \%)$ & $97(47.8 \%)$ & \\
\hline Tumor within Milan Criteria & $90(14.9 \%)$ & $74(18.6 \%)$ & $16(7.7 \%)$ & $<0.001$ \\
\hline Overall Survival (Years) & $2.5 \pm 2.8$ & $3.0 \pm 3.1$ & $1.6 \pm 1.9$ & $<0.001$ \\
\hline
\end{tabular}

Abbreviations: BMI: body mass index, HIV: human immunodeficiency virus, INR: international normalized ratio, MELD: Model for End-Stage Liver Disease, APRI: AST to Platelet Ratio Index, HCV: hepatitis $\mathrm{C}$ virus, $\mathrm{AlH}$ : autoimmune hepatitis. PBC: primary biliary cholangitis, PSC: primary sclerosing cholangitis, HC: hemochromatosis, A1ATD: alpha-1-antitrypsin deficiency, NAFLD: non-alcoholic fatty liver disease. 